\title{
Roles and Practices of Women in Social Development on Southwest Border of China

\author{
Tianyu Wang ${ }^{1, *}$, Jiangyan $\mathrm{Zi}^{2}$
}

${ }^{1}$ Chinese Language and Culture College, Yunnan Normal University, Kunming, 650500, China
${ }^{2}$ School of Education \& Management, Yunnan Normal University, Kunming, 650500, China

* Corresponding Author: Tianyu Wang

Keywords: Southwest border, Social development, Women roles

\begin{abstract}
The production and life of the women in the southwest border of China are mainly based on the family organization. As an important member of the family, women play an important role in the family life. They gave birth, raised and educated their children, making a fundamental contribution to the family and society development. After the founding of the people's Republic of China, the women on the southwest border gradually became the participants of social public life. The local government should take measures to encourage the women to participant the social life more actively.
\end{abstract}

\section{Introduction}

The southwest border region includes the provinces of Tibet, Yunnan and Guangxi along the traditional geographical scope. Southwest border area is southwest frontier Chinese for opening to the outside world, is an important channel to the South and Southeast Asian countries, is an important link of communication market two ocean, both at home and abroad, which has an important position in the whole Chinese geopolitical economic strategy pattern. Especially in recent years, the proposition of "The Belt and Road" and other areas the development strategy of this special region is subject to strong concern at home and abroad. Gender role is a social role in the sex based on the standard of quality. It is due to the characteristic of people of different sex which conform to certain social expectations, including different attitudes, personality characteristics and social behavior of men and women holding. Social status refers to the position of a certain social group or individual in a social or social structure in a certain historical stage. The social status of women in the southwest border refers to the position of the women in the southwest border in the social relations and social structure. The status and rights of modern society caused by gender differences in the increasingly narrow, the role behavior norms become flexible and optional more, but because of the role of cultural heritage, people of different expectations of gender roles are still under the influence of traditional culture, especially in the two turn of the century, both sexes experience more role confusion and role conflict serious than in the past, face re selection behavior. Therefore, it is necessary to study the gender roles of women in the southwest border.

\section{Social Roles of Women on Southwest Border of China}

Bear Children. The birth is the most important content in the traditional role of women. It is the necessary condition for obtaining social and family recognition, and it is also the ultimate embodiment of the whole social man. In the past forty days after the birth of her first child, the parents of the southwest border prepared her earrings and rings. The day of the many maternal plait comb with two braids, no longer have the forehead hair and makeup to wipe Rouge for the first time. Prior to this, the girl is not allowed to make-up. When she has the appropriate number and sex ratio of children, she has a certain degree of prestige in the family, in the community has become a respected mother. When her son married, after she became a mother, her status has gradually reached its peak. A woman who is not able to bear a child, even a woman who does not give birth to a boy, or is removed from the role of a wife by her husband, or a child who has adopted a child. Most people are anxious for her husband to marry, so mothers are eligible, as women make up for their inability to 
save the marriage to failure. The influence of modern marriage culture, family roles of women has changed from single, auxiliary and passive state to a new role with autonomy and initiative. This is inseparable from the development of new family relationships in china. Today, however, the role of rural women's mothers can be said to be open and double, and the family must bear the corresponding social roles. The role of women as mothers in the southwest border has also undergone a different change. The traditional mother's role is closed, confined to a single family, what she does is to have children, housework.

Undertake Housework. Housework is another important aspect of women's family roles. Part of the southwest border family gave birth to a girl, put a broom on the girl's head, that his daughter will grow up with the housework, to become a good housewife good friends. This is the embodiment of women as the sole undertaker of housework. Housework generally include cooking, washing, spinning, weaving, sewing, cleaning, management and so on children. Housework is trivial and complex, but there are no obvious essential benefits. Therefore, participation in social production and the women were always busy with housework to feed her father or husband, labor is not recognized. Naturally, a woman in the family with their identity, role and different responsibilities. In the traditional family, the new bride is mainly used to do housework took mother-in-law, mother-in-law started relatively quiet, command of housework, help daughter-in-law. After a little understanding of her daughter, it is necessary to bring siblings to help her mother tidy the room. So far in some remote rural areas, many twelve, three-year-old girl gave up early school education, at home to do housework, take care of siblings, and learn to be a housewife. The traditional role of the content of the unity of their role in the learning process is relatively short, very early into the adult society. On the whole, women are still the main undertaker of housework, and the burden of housework is still heavy. Women in the study, communication, entertainment and other aspects of free time is obviously insufficient. The main content of the women's housework in the southwest border cities is shopping, laundry, cooking, cleaning the room, helping children with homework and so on.

Participate in Social Life. After the founding of new China, the Constitution clearly stipulates the equality of men and women. As the owner of the means of production, both men and women participate in the political, economic, cultural and other activities of the state, which guarantees the social status of women from the economic foundation, the system, the law and the policy. In the new social system, the traditional social division of southwest borderland society has been broken, women in society and family life from the man belongs to the era has become history, women themselves have no longer satisfied as mother, wife and daughter's role in the family. The change of the social division of labor has made a profound change in their social roles. With their new social roles in political, economic and cultural life of society at the same time, on the one hand, contributed to the local economic development, on the other hand, also show courage should be women in southwest frontier and talent to prove their abilities. The main concern of the southwest frontier women on the major affairs at home and abroad is mainly in five aspects: social security, housing, social security, health care reform and financial crisis. Among them, the highest concern of social security issues, followed by health care reform. There are some differences between urban women and rural women concern, urban women pay attention to the order of social security, social security and housing problems, while rural women pay attention to the order of social security, health care reform and rural issues. There was no significant difference between male and female, but men and women have different ways of obtaining information. Network is a common way for men and women to obtain information, especially in cities and towns. In addition, women more information through friends, family, acquaintances, men are more dependent on the press.

\section{Thinking on the Transformation of Social Roles of Women on Southwest Border of China}

Transform Birth Idea. The changes of the objective social policies and family patterns have an external constraint on the family role play of the women of childbearing age. These roles restrict and affect their fertility concept. It restricts the family mode, is the core of the women of the family than the main family and united family in women of childbearing age to play a more active role in the 
family, which makes their fertility concept is relatively more reflects the wishes of the individual. The main family and united family in women of childbearing age in the family role more from spouses and elders and other family members to limit their birth concept reflect more family members will. The change of social culture is a historical process. It changes with the development of society and their own characteristics, we cannot completely eliminate the cultural characteristics of the previous period in a period of time, because the culture of different periods is the succession, the culture in this period is the inheritance and innovation of culture before during the period of. Even if the new cultural characteristics have covered the old cultural characteristics, people's ideas cannot be left in the immediate change. On the social and cultural changes, changes in the southwest border women's family roles and attitudes in theory is the kernel should be synchronized, but the ideas and social individual culture often appear some synchronization, therefore, accept and internalize the eventual development of the two depends on a body for changing cultural environment. The education here includes both school education and community education. The change of the family role and the change of fertility concept is a complicated process. There is a complementary relationship between the two, but also directly or indirectly affected by the change of ideas in the southwest border areas.

Socialize Household Chores. Housework is not a woman's vocation. With the deepening and expanding the social production level and scale, housework socialization day by day, in different families, different men and women, and the rationality of division of labor will increasingly depend on the personal qualities and interests, rather than gender. The socialization of housework is a long and tortuous process, which requires the corresponding changes of the society, the structure and the family. This process is bound to be affected by many factors, such as the level of national economic development, the level of household consumption in the family. There are two forms of household service. They are the national and collective labor service companies and the streets of the life of the service industry. The staff recommended housework, short-term, temporary and perennial regularly for the user and the latter is introduced; the business agent, repair business, leasing and sales operations, and provide a variety of daily life services, care for the elderly and patients, family run kindergartens. The characteristics of the service industry is the service and business combination, low cost, Business Hours long, so that the residents can buy clothes, sewing and general commodity and food, and carrying out street children. Socialization of housework is an important part of women's Liberation in the southwest border, and has become an important social goal. It can fundamentally reduce the southwest border women in household labor intensity, so that they have more time for physical and mental development, there are abundant energy in the social production to improve themselves, so as to improve women's social and economic status.

Take an Active Part in Social Life. The southwestern border of the governments at various levels shall implement the basic national policy of equality between men and women and further enhance the sense of responsibility and initiative to further understand the importance of enhancing the social status of women in economic and social development in Xinjiang, the whole process of the gender consciousness into the economic and social development policy formulation, implementation and evaluation, to carry out the implementation of the legitimate rights and interests of women, promote the all-round development of women social undertakings. We will vigorously advocate and promote equal, civilized and progressive gender culture as an important part of the construction of advanced socialist culture. The government should strengthen the leadership of the Party cadres, educators, media practitioners of gender awareness training, strengthen the guidance and supervision of the media especially the mass media television, radio and Internet, optimize the social environment of public opinion of women's political participation in the entire society, men and women shared social and family responsibilities such as gender equality in social culture. We actively create a social and cultural environment conducive to women's development. We should give full play to the role of women's federations at all levels, improve policies and mechanisms for women to participate in political decision-making and social and economic management, improve women's awareness of participation in politics, and promote the development of women's social undertakings. To ensure that the party and government organs at all levels in the number of women to account for a certain proportion, gradually to give priority to women under the same conditions, the women in the party 
and government organs at all levels in the proportion of the rise, change the status of serious imbalance in the proportion of men and women in the party and government organs, to ensure women's political discourse, in a variety of major decisions should reflect women's voices and will. To enhance women's social and political status, give full play to the role of women's organizations at all levels to help the majority of women in unity, education and the regular and non-regular education and training on women's health, psychological counseling, occupation skills, provide a powerful spiritual motivation and intellectual support for the southwest border of women comrades.

\section{Conclusion}

Women living in the southwest border areas play the important role of bearing children and undertaking the housework in family life. They also take part in some work in the social public life. In the future development, the government should encourage and support the women on the southwest border to learn more cultural knowledge and change traditional ideas to participate in social life more actively to become the real "half the sky".

\section{Acknowledgement}

This research is the periodical result of the project named "Research on the Problems of Female Development and Society Stability in the Ethnic Areas in South-west Border” funded by National Social Science Foundation in China in 2015 (Grant No. 15CMZ045).

\section{References}

[1] Liang Liping, Wang Yanping, A Study of the Development of Female Talent Groups: An Analysis Based on Questionnaires of the Third Phase Chinese Women s Social Status Investigation in Shanxi [J]. Journal of Shanxi University (Philosophy \& Social Science), 2014, 37(3): 123-128.

[2] Wang Jinling, Jiang Jiajiang, Five Challenges Facing the Women's Development and Pursuit of Gender Equality in China: A Case Study in Fujian Province [J]. Journal of Yunnan Nationalities University (Social Sciences), 2013, 30(5): 64-69.

[3] Tang Xueqiong, Zhu Hong, The Impact of Tourism Development on the Social Gender Concept of Ethnic Women under Aboriginal Patriarchy System Based on the Comparative Study of the Ethnic Groups of Sani, Dai, and Hani [J]. Human Geography, 2010(1): 123-128.

[4] Lu Chunping, The Characteristics of Women's Social Organization and Governance Function in Northwest Minority Regions [J]. Guizhou Ethnic Studies, 2014, 35(1): 36-38. 